\title{
Research on Interior Decoration of Residential Buildings in the Central Shaanxi Plain*
}

\author{
Shasha Cai \\ Arts College \\ Xi'an FanYi University \\ Xi'an, China
}

\begin{abstract}
With the improvement of material levels, people's requirements for home are getting higher and higher. This paper mainly studies the forms and interior decoration elements of buildings in the central Shaanxi plain, as well as the application and refinement of decorative elements in modern indoor spaces. In the end, this paper summarizes the influence of decorative elements in residential buildings on modern interior decoration techniques.
\end{abstract}

Keywords—residential architecture; interior design; decorative elements

\section{INTRODUCTION}

The central Shaanxi plain is the birthplace of the Chinese nation and the center of economics and culture in Shaanxi province. Its long history and rich geographical resources have created the simplicity and sediment of the architectural style. The interior decoration elements are diverse and the decorative effect is obvious. It is still used in many modern "new Chinese-style" interior design styles.

\section{REsidential BUILDING IN THE CENTRAL SHAANXI PLAIN}

Most of the residential buildings in the central Shaanxi plain are in the form of courtyards. The rectangular independent courtyards set up the entrance hall from the entrance to the wing rooms on both sides of the courtyard. And then, it finally enters the main courtyard. The main room is set in the innermost part of the yard, and its privacy and master status are reflected. The wing room is a place for the children to live in. It is located on both sides of the yard. The hall is the most important part in the interior design of the building. The main function is to meet guests and gather meals. The interior decoration design is also the most prominent. The residential buildings in the central Shaanxi plain generally have a width of 8-10 meters and a depth of 20 meters, forming a narrow courtyard layout form, and the layering and privacy are well reflected.

The construction materials of residential buildings in the central Shaanxi plain are mainly composed of soil, wood,

*Project number: 18JK0999

Project name: Study on Interior Decoration of Residential Buildings in the Central Shaanxi Plain

Project source: Shaanxi Provincial Department of Education 2018 Annual Special Scientific research Plan brick and stone. Rammed earth is a building material commonly used by most ordinary people, and is used mostly in floor decoration. A small number of wealthy people choose to pave and paste with brick or stone, and the form is more beautiful. The wall is generally treated with soil or blue bricks, and the adobe is built on the wall, and the wall is painted with grass mud. The wood of residential buildings in the central Shaanxi plain is less used due to climatic conditions. It is generally used in the top and interior decoration of indoor second-floor lofts. And its texture is softer and more comfortable.

\section{THE INTERIOR DECORATION OF RESIDENTIAL BUILDINGS IN THE CENTRAL SHAANXI PLAIN}

In the history and culture of China, the buildings provide a space for the host to shelter from the wind and protect people from the natural disasters such as wind and rain. And it is a symbol of the status, identity and family glory of the master. The ancient architecture of China is a mortise-tenon structure. In the process of construction, sharp corners are inevitable. In order to make the styling more beautiful, the craftsmen and artists have carved a lot of auspicious figures on the building components and external styling. The meaning of the architectural space will be better. If the Chinese pray for more sons and more blessings, they will use the patterns of "Kylin sending the child" and "Avalokitesvara sending the child" to express the expectations of the heart. They use the pattern of "two mandarin ducks are tumbling merrily" to express the love of the husband and wife. People pray high official and richness with the pattern of "clouds and road" to express the expectations and longings. The application of all decorative patterns in architecture is the manifestation of its spiritual culture. Also, it is the integration of architecture and art, and the integration of architecture and life.

\section{A. Top Surface Decoration}

There are two kinds of treatment methods for the interior decoration of residential houses in the central Shaanxi plain. First, the wood is used as the raw material in the form of a well-character as the decorative shape on the top surface. The top shape has strong sense of hierarchy and clear division of space. The other is to make the folk decorative paintings, paintings, stickers and other elements on the top 
surface for decoration. The decorative effect is strong, and the cost is low. The wood is relatively rare in the central Shaanxi plain, and it is expensive. The climate is dry, and ordinary people rarely use it. It is usually used in a few wealthy families.

\section{B. Wall Decoration}

The wall plays a role of covering space, enclosing space and partial load-bearing in the building space, and is a barrier that utilizes space and divides space. The wall decoration in the interior design of residential houses in the central Shaanxi plain is in the form of folk crafts, such as the posting of peasant paintings in Huxian County, and the posting of folk paper-cut on walls and windows, doors and furniture. The maoshao facial is unique. Its paintings are exaggerated and various. The content is taken from the folk legends and modeling of the justice figures. People hang it on the interior wall as a decorative item. It not only has the effect of exorcising evil and avoiding evil, but also expresses the beautiful expectations of praying for happiness and fortune. Facial makeup is often seen in the shape of folk lifestyle goods. The embroidery is a unique form of folk art in Shaanxi, which appears in indoor walls and has strong decorative effect.

\section{Door and Window Decoration}

The buildings must have the position of the door and window. The functions of the door and window in the buildings are mainly ventilation, lighting and dividing space. In ancient residential buildings, the shape of doors and windows is basically square, and the materials are mostly made of wood. In order to make the door and window shape more vivid and diverse, the ancients carried out wood carving patterns on them to enrich the style. Plants, animals, geometry, utensils and other patterns are often used to decorate the door leaves. Due to the dry and cold climate in the central Shaanxi plain, the sand is large and the panes are densely arranged. Influenced by the Taoist culture, people generally use the "bat pattern" and "dragon pattern" in the middle of the pane. And they are quite elegant in terms of quantity. Generally, one, five, and nine are used for quantitative reference. A bat stands for the meanings of "one creates two, two creates three, and three creates all things". Five bats represent the five blessings, bats are the homonyms of blessings, all of which are beautiful. Nine are the biggest in odd numbers. That is to say, it represents the most. In addition to this, people also use the words "blessing" (福), "longevity" (寿), "Double Happiness" (囍) and other words in the pane to express the beautiful expectations for life.

\section{Floor Decoration}

The floor decoration is mainly reflected in the style of the materials. The floor in the residential buildings in the central Shaanxi plain is mainly composed of blue bricks. People use different combinations of blue bricks to form a pattern with strong decorative effect, which enriches the interior space. In addition, the stone is also used in a small amount in the residential floor in the central Shaanxi plain. The "stone carving" is the inheritance of the craftsmanship in the central
Shaanxi plain. The carving of the auspicious patterns on the stone floor is exquisite and the decoration effect is strong.

\section{E. The Decoration of Partition Wall and Screen}

The partitions are usually in the form of virtual partitions in the interior space. The partitions in the interior spaces of ancient residential buildings are mostly in the form of grass and wood, creating the virtual, smart and transparent dividing space. The screens in ancient buildings are mainly used to divide the space and block the sight. It is generally placed below the beam. The front of the screen is the reception area, and there is a channel that enters another space in the back. The decorative effect of the screen is extremely strong. Generally, wood is used as the raw material. The carvings of plants, animals, scenes, figures, utensils, etc. are carried out on the screen. The decorative techniques are diverse, and the pattern categories are rich.

\section{SIGNIFICANCE OF THE STUDY ON INTERIOR DECORATION OF RESIDENTIAL BUILDINGS IN THE CENTRAL SHAANXI PLAIN}

The central Shaanxi plain is the birthplace of China's history and culture. The protection of material and cultural heritage also includes the protection and restoration of residential buildings and ancient architectural forms. Architecture is the soul of a city and the image of the city. It can show the cultural heritage of the city through its form, materials and layout. People can understand the city more directly and quickly. Under the modern metropolitan environment, the appearance of most modern cities is the same as the wrapping of concrete and glass walls. There is less regional culture in the city. This is very terrible. The nationality is the world. Shuttling in such cities, how can reflect its nationality, regionality and uniqueness? It is what we should reflect as a design worker. It is incumbent for the protection of local residential buildings from destruction and demolition.

Interior decoration is the embodiment of the interior space of buildings. The effective decoration in its structural part can greatly enhance the rendering and emotional transmission of the indoor space atmosphere. The study of interior decoration of residential buildings provides great reference to the support and methods of modern interior design, and provides an effective basis for the formation of the "new Chinese-style" interior space style.

\section{THE INHERITANCE OF INTERIOR DECORATION OF \\ RESIDENTIAL ARCHITECTURE IN THE CENTRAL SHAANXI PLAIN IN CONTEMPORARY INTERIOR SPACE DESIGN AND DECORATION TECHNIQUES}

\section{A. References for Decorative Patterns}

In ancient Chinese residential buildings, there are many auspicious patterns with different meanings as decorations in the architectural body or indoor space. The patterns are full and rich in content. It has profound meanings. Modern residential buildings and "new Chinese-style" interior design styles follow the ancient decorative patterns in the design 
process, and some are used directly in their own designs. For example, during the Chinese New Year, people will post the figure of "blessings" (福) on the windows to express good life. "Blessings" (福) is the decorative pattern mostly used in modern interior space. Some are the refinement and derivation of ancient auspicious patterns, such as the design of many modern indoor panes and thresholds. The ancient decorative patterns are deconstructed and reorganized to create a modern residential building that meets the aesthetic needs of modern people. It not only inherits the ancient culture, but also meets the modern environment and aesthetic requirements.

\section{B. Inheritance of Interface Decoration Types}

The interior space is divided into two parts during the design process: hard decoration and soft decoration. The hard decoration is the decoration of each interface in the room. The soft decoration is the selection of furniture, accessories and plants. The interior decoration is done on the basis of hard decoration. The decorative part of the modern interior space is still completed in various interfaces in the interior, such as decoration content on the top surface, the ground surface, the wall surface, the partition and the screen. It appears in the form of art.

In the past materials, the understanding of residential buildings is more about the structure and shape of the building. The interior decoration of the building is poorly understood. With the change of modern design concept, the design concept of "ignoring fitment, focusing on decoration" has influenced our understanding of the design. The designers put more energy into the later soft assembly decoration. The design of the soft decoration also accounts for the proportion of our design. Studying the interior decoration of residential buildings provides the theoretical basis for the design of modern space decoration and furnishings.

\section{CONCLUSION}

With the increasing demands of modern people for their homes and public spaces, the interior design profession has been well developed and applied in this field. On the one hand, it can meet people's gradually improving aesthetic requirements. On the other hand, it can also satisfy people's pursuit of the quality of life. However, the study of residential buildings and interior decoration in the central Shaanxi plain has largely influenced and promoted the pace of modern interior space design. It is undoubtedly a good choice to use the decorative techniques of the predecessors in the "new Chinese-style" interior space design. It preserves the decorative techniques in residential buildings and also integrates new ideas. It provides a guarantee for modern interior design space. The nation is the world. The ingenious use of the design elements in the local residential buildings is a respect for our design.

\section{REFERENCES}

[1] Zhang Bitian, Liu Zhenya. Shaanxi folk house. Beijing: China Building Industry Press, 1993.

[2] Liu Senlin. Chinese furnishings — Traditional residential interior design [M]. Shanghai: Shanghai University Press, 2006.

[3] Liu Yan. Application of Chinese traditional residential interior decoration concept in contemporary living room furnishings [D]. Xi'an University of Architecture and Technology, 2008.

[4] Wang Qijun. Chinese architectural decoration language [M]. Beijing: Mechanical Industry Press, 2008.

[5] Liu Senlin. Chinese decoration - Traditional residential decoration artisans [M]. Shanghai: Shanghai University Press, 2004.

[6] Wang Qijun, Tian Yong, Hu Kedan. Decorative furnishings [M]. Beijing: China Building Industry Press, 2007. 